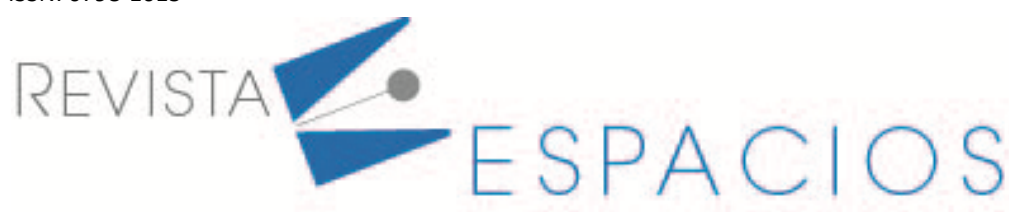

Vol. 42 (06) $2021 \cdot$ Art. 7

\title{
Tendencias y desafíos de la tributación en Colombia y América Latina*
}

\section{Trends and challenges of taxation in Colombia and Latin America}

\author{
VARGAS-RESTREPO, Carlos M. ${ }^{1}$ \\ PEÑA-GUTIÉRREZ, Aura E. ${ }^{2}$
}

\begin{abstract}
Resumen
Este articulo presenta un análisis de las tendencias y desafíos de la tributación en Colombia y Latinoamérica. Fue una investigación cualitativa sustentada en el método hermenéutico. Se evidenció el carácter fiscalista de las reformas tributarias y sus fundamentos: fortalecimiento de la tributación internacional; incentivos al capital, mayores gravámenes a las rentas de trabajo y consolidación de la tributación indirecta. Algunas tareas pendientes son potenciar el efecto corrector de los impuestos y fortalecer la tributación verde.

Palabras clave: tributación, redistribución, desigualdad, justicia tributaria.
\end{abstract}

\begin{abstract}
This article presents an analysis of the trends and challenges of taxation in Colombia and Latin America. It was a qualitative investigation supported by the hermeneutical method. The fiscal character of the tax reforms and their foundations was evidenced: strengthening of international taxation; incentives to the capital, higher taxes on work incomes and consolidation of indirect taxation. Some pending tasks are to enhance the corrective effect of taxes and strengthen green taxation.

key words: taxation, redistribution, inequality, tax justice
\end{abstract}

\section{Introducción}

La comprensión de las tendencias y desafíos del fenómeno tributario en Colombia y América Latina, demanda una visión retrospectiva como vía de entendimiento de sus génesis. En tal sentido, las directrices derivadas del denominado Consenso de Washington brindan algunos elementos para el efecto. Dentro de estas directrices se cuentan el promover la estabilidad macroeconómica de los Estados y el equilibrio de sus finanzas públicas; limitar

\footnotetext{
* Este artículo es uno de los resultados de la investigación doctoral con título "El concepto de justicia tributaria ante el debate de la equidad e igualdad. Una resignificación basada en el enfoque rawlsiano".

${ }^{1}$ Contador Público de la Universidad Católica de Oriente, Especialista en Gestión Tributaria de la Universidad de Antioquia, Magíster en Fiscalidad Internacional de la Universidad Internacional de la Rioja (España), Magíster en Gestión de Organizaciones de la Universidad EAN y Université de Québec à Chicoutimi (Canadá); Doctor en Ciencias Contables de la Universidad de los Andes (Venezuela). Docente investigador adscrito al Grupo FACEA de la Facultad de Ciencias Económicas y Administrativas, Universidad Católica de Oriente. E-mail: cvargas@uco.edu.co.

${ }^{2}$ Contador Público de la Universidad de Los Andes (Venezuela). Profesora en Educación Integral Mención Ciencias Sociales de la Universidad Pedagógica Experimental Libertador (Venezuela), Abogado. M.Sc. en Administración Mención Gerencia de la Universidad de los Andes (Venezuela). Doctora en Educación Mención Administración, Postdoctora en Normas Internacionales de Información Financiera Universidad de Los Andes, Venezuela. Docenteinvestigador de la Facultad de Ciencias Económicas y Sociales de la Universidad de los Andes (Venezuela). E-mail auraelena0659@gmail.com.
} 
la intervención estatal a través de políticas de privatizaciones y su papel regulador; desregular los mercados; incentivar procesos aperturistas y de liberalización de los mercados; e implementar reformas tributarias enfocadas en privilegiar impuestos que aseguren la neutralidad, es decir, que no generen distorsiones en las decisiones de los agentes económicos, sobreponiéndolos a los impuestos progresivos, y reformas que contemplaran ampliación de bases imponibles y aumento de tarifas en los impuestos que gravan el consumo y que al mismo tiempo disminuyeran los tipos de los impuestos sobre las ganancias, especialmente a las personas jurídicas. Frente a esto, Restrepo (2005) expone que el papel de la hacienda pública y del Estado se reduce a "un mínimo de intervención en la actividad económica y un máximo de neutralidad frente al comportamiento de los agentes económicos. (p. 23).

Estos señalamientos, conjuntamente con la globalización económica y el desarrollo de los mercados financieros y de capitales, ha incidido en la modelación de los sistemas impositivos los cuales en las últimas cuatro décadas han enfatizado en los impuestos indirectos por sus bondades en cuanto a economía, eficiencia recaudatoria y no afectación del capital, pues se conoce, de acuerdo con la teoría y práctica fiscal, que este tipo de gravámenes son repercutidos hacia el consumidor o usuario final sin que generen impactos sobre los beneficios empresariales.

A pesar de estos esfuerzos, la región presenta una presión tributaria relativamente baja -al comparársele con países OCDE- (ver gráfico 1) y se han configurado sistemas tributarios regresivos que lesionan el principio de equidad tributaria y que generan inseguridad jurídica debido a los constantes cambios en dichos sistemas.

La equidad tributaria supone la definición de criterios de diferenciación de los sujetos pasivos en orden a establecer sus cargas impositivas. Generalmente, se limita a la capacidad contributiva de dichos sujetos, pero deberían considerarse otros aspectos tales como condiciones socio-económicas, conformación del núcleo familiar, ubicación geográfica, número de personas a cargo o nivel de formación, entre otros.

Ahora bien, se reconocen dos conceptos de equidad en materia tributaria: equidad horizontal y equidad vertical. Siguiendo a Stiglitz (1986), "un sistema tributario es equitativo horizontalmente si los individuos que son iguales en todos los aspectos relevantes reciben el mismo trato" (pág. 449). Por su parte, la equidad vertical exige que los individuos que ostentan mejores condiciones, es decir, que tengan mayor capacidad contributiva, deben soportar cargas impositivas más altas respecto de aquellas personas con menor capacidad de contribución. Este segundo concepto de equidad es el que mejor desarrolla la diferenciación de contribuyentes y permite materializar sistemas tributarios justos.

Ligado a esto, la justicia tributaria demanda la certeza frente a las reglas que sustentan los sistemas impositivos de tal manera que si se modifican contantemente los ordenamientos se provoca inseguridad jurídica limitando el derecho de los contribuyentes de implementar estructuras de planificación fiscal y economías de opción.

Ahora bien, un breve análisis de la realidad socioeconómica de América Latina a partir de lectura y comprensión del contexto junto con documentos de la CEPAL (2019), OCDE (2016), OCDE (2020), Naciones Unidas (2015), entre otros, permite señalar que se trata de una región heterogénea, con marcadas disparidades y, en general, con las siguientes características:

- Economías frágiles por la inestabilidad política, debilidad institucional, altos niveles de informalidad, falta de legitimidad y de confianza en los gobiernos, entre otros.

- Problemas socioeconómicos estructurales, manifestados en altos niveles de pobreza y al mismo tiempo concentración de la riqueza en pocos agentes, lo que la coloca en un estadio de alta desigualdad, con la imposibilidad de acceso a derechos fundamentales (educación, salud, vivienda, servicios básicos, etc.) por una porción importante de la población. 
- Problemas emergentes asociados al cambio climático y destrucción de los servicios ecosistémicos, extracción de recursos naturales y no renovables de manera ilegal, narcotráfico y violencia, la pandemia por el virus SARS-CoV-2, entre otros.

\section{Gráfico 1}

Relación de ingresos tributarios y el PIB (Ingresos tributarios totales como \% del PIB) en los países ALC, 2017

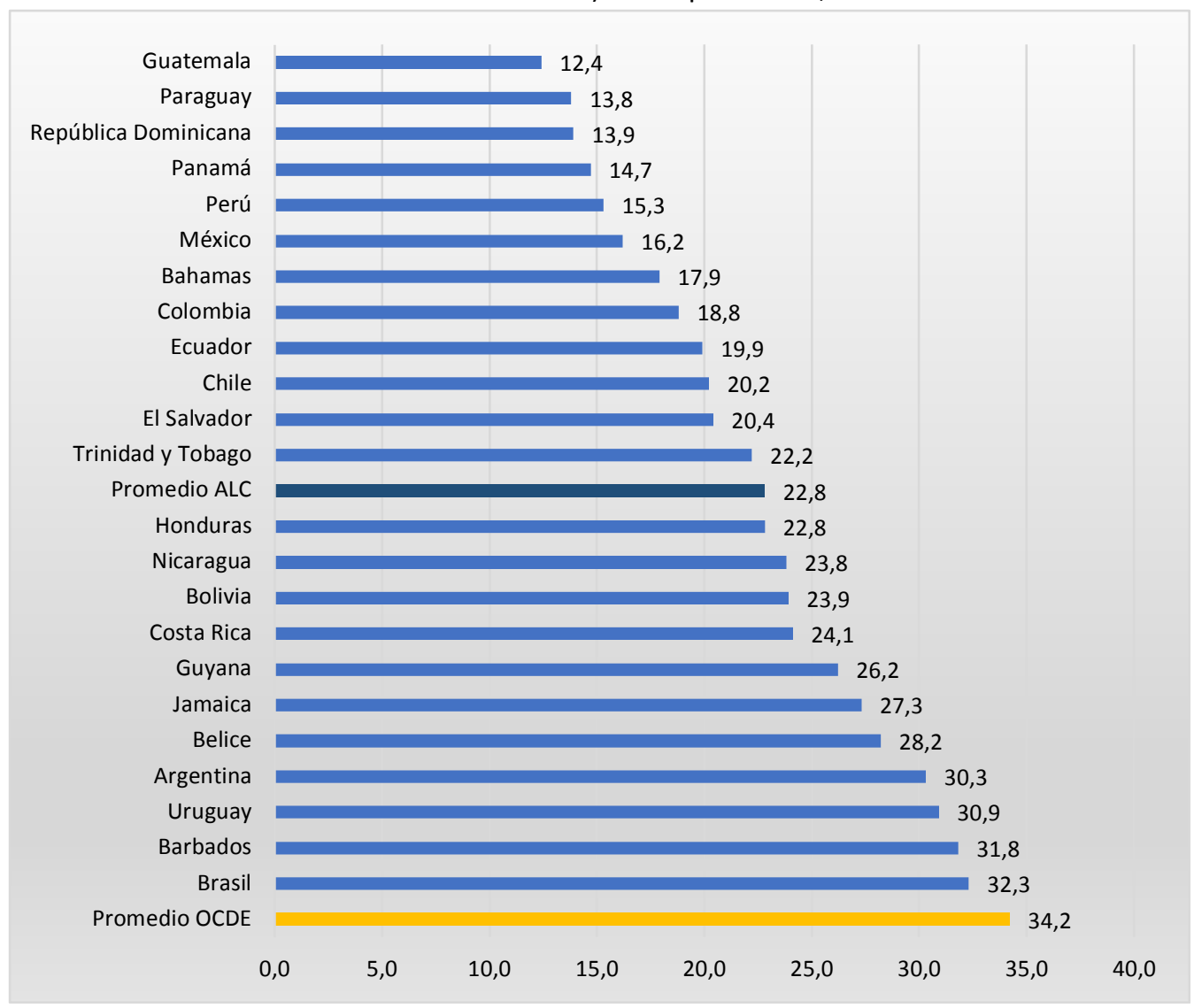

Fuente: Elaboración propia (2020) a partir de OCDE (2019)

El escenario descrito anteriormente, pone en evidencia la necesidad de debatir sobre la efectividad de la política fiscal en Colombia y América Latina, tanto en términos del fortalecimiento de los fiscos como de su efecto redistribuidor y corrector de las brechas de desigualdad. Este artículo pretende aportar en este sentido, mediante la descripción de las tendencias del fenómeno tributario en los últimos años, algunos puntos que constituyen desafíos y lo que se consideran tareas por cumplir por parte de las haciendas públicas. Las lecturas del contexto y la comprensión del fenómeno se hacen alrededor del principio de justicia tributaria, sustentado en criterios de igualdad, equidad y progresividad, entre otros.

Lo anterior cobra mayor relevancia al considerar que en la Cumbre de Naciones Unidas de 2015 se aprobó la agenda para poner fin a la pobreza y a la desigualdad a escala mundial para el año 2030. El documento final de esta cumbre se intituló "Transformar nuestro mundo: la Agenda 2030 para el desarrollo Sostenible" y contiene un compendio de 17 objetivos del desarrollo sostenible -ODS- (desagregados en 169 metas) que abordan asuntos de tipo económico, social y ambiental, entre los cuales se encuentran la promoción del desarrollo humano, la lucha contra la pobreza y la miseria extrema, la búsqueda de la seguridad alimentaria, la educación inclusiva, la igualdad de género, la disponibilidad de agua y energía, el empleo digno y el crecimiento económico, entre otros. Estos ODS se extrapolan al plano local por parte de los gobiernos nacionales y subnacionales que trazan metas en sus planes de desarrollo, de alguna manera articuladas con los mismos. 
Como quiera que resulte lógico, el cumplimiento de los ODS y la ejecución de los planes de gobierno demandan recursos para su financiación. En tal sentido, puede señalarse respecto de los ODS, que en el consenso de Naciones Unidas se identificó como principales fuentes para ello: i) las donaciones, ii) los flujos de inversión extranjera y, iii) los recursos públicos internos, dentro de los que se encuentran los tributos. En este consenso de Naciones Unidas se acordó enfatizar sobre esta tercera fuente de recursos dadas sus ventajas en términos de estabilidad y mayor control por parte de los Estados. De facto, en el objetivo 17.1 de la agenda señalada se establece como meta: "Fortalecer la movilización de recursos internos, incluso mediante la prestación de apoyo internacional a los países en desarrollo, con el fin de mejorar la capacidad nacional para recaudar ingresos fiscales y de otra índole" (Naciones Unidas, 2015, p. 30). (el resaltado es propio).

Lo anterior supone implícitamente el fortalecimiento de los principios del sistema impositivo lo cual resulta favorable frente a una sociedad y una base empresarial que demandan mayor equidad y progresividad en materia tributaria, tanto en el establecimiento de exacciones como en la asignación del gasto público.

Por otra parte, los diferentes países enfrentan grandes desafíos en materia fiscal en orden a incrementar sus ingresos internos para financiar su gasto público y por ende, dar cumplimiento a los ODS. Entre tales desafíos se encuentra adelantar modificaciones en los ordenamientos jurídicos, reestructurar las instituciones, redefinir la estructura de gasto público, asegurar un crecimiento económico sostenible y sustentable, entre otros.

El artículo presenta en un primer momento, el análisis de la dinámica y las principales tendencias que ha seguido la tributación en Latinoamérica en los últimos años, principalmente, desde la década del setenta cuando emergió y rápidamente se consolidó el modelo económico imperante conocido como capitalismo bajo la ideología neoliberal.. Como se podrá observar, muchos problemas de tipo económico, social y ambiental no han sido resueltos y por el contrario se han acentuado, razón por la cual se plantea, en segundo término, los desafíos que deberían atender las haciendas públicas en los próximos años en orden a potenciar el efecto correctorredistribuidor que tienen los impuestos y, en consecuencia, lograr crecimientos económicos sustentables, justos y equitativos.

\section{Metodología}

La presente investigación tuvo como objetivo el análisis de las tendencias y desafíos de la tributación en Colombia y América Latina. El desarrollo metodológico se abordó desde un diseño cualitativo, con sustento en el método hermenéutico que requirió la obtención de información y su respectivo análisis mediante la triangulación. La técnica predominante fue la revisión documental la cual permitió conceptualizar las categorías que sirvieron de fundamento en el proceso investigativo.

Lo anterior permitió construir una matriz categorial con el fin de identificar los principales elementos que subyacen en la modelación de los sistemas impositivos de Colombia y Latinoamérica en los años recientes y al mismo tiempo los desafíos que estos enfrentan, los cuales se derivan de las problemáticas económicas, sociales y ambientales presentes en la región o que emergen acorde con el contexto histórico de la misma.

\section{Resultados y discusión}

\subsection{Principales tendencias de la tributación en Colombia y América Latina}

Un señalamiento previo que se debe hacer es que si bien es cierto existen heterogeneidades entre los países latinoamericanos y ciertas particularidades, se pueden identificar tendencias generales en materia impositiva seguidas por la mayoría de ellos. En este sentido, una primera tendencia de la tributación en Colombia y América Latina la constituye el hecho de las constantes reformas a los ordenamientos tributarios que las convierten en fiscalistas; es decir, más centradas en el recaudo y menos en ofrecer soluciones socioeconómicas de largo plazo. 
Así, su carácter es coyuntural en orden a atender el déficit presupuestal ocasionado por múltiples fenómenos del entorno nacional y por situaciones (o imposiciones) del entorno internacional. De ahí que, cada reforma no logre conjurar el déficit, ni genere los recursos suficientes para atender el gasto público. Gómez (2006) confirma estos planteamientos cuando señala lo siguiente

En estas dos últimas décadas, la situación tributaria de América Latina ha experimentado profundos cambios estructurales. Estas modificaciones no han sido armónicas y permanentes, sino que, por el contrario, desequilibradas y continuas, porque en todos estos años no se ha logrado un adecuado balance de la distribución de la carga tributaria entre los distintos estratos socioeconómicos que permita llegar a un cierto grado de consenso social en torno a ella, y tampoco se han podido establecer patrones definitivos en cuanto a la participación de los distintos niveles de gobierno en la composición de la presión tributaria en aquellos países en que existen potestades tributarias concurrentes. Los cambios también han sido continuos, porque los procesos de reforma, tanto de la estructura como de su administración, han debido reiterarse al no ser posible lograr el nivel de recaudación suficiente como para satisfacer las demandas del gasto público y alcanzar una sostenibilidad y solvencia permanentes. (p. 41).

De lo anterior, se puede inferir que las constantes reformas tributarias también generan limitaciones para interpretar y aplicar la norma fiscal, puesto que en el caso de algunos países complejizan el sistema impositivo y suponen la existencia de abundante regulación y el origen de interpretación oficial de la regulación, a través de la doctrina y fallos jurisprudenciales emitidos por las instancias que integran la rama judicial en cada Estado. Baer (2006) anota en este sentido que la "tendencia en algunos países ha sido hacia la creciente complejidad de los sistemas tributarios" (p. 133). Agrega esta autora que la modificación de la regulación fiscal

ha creado una situación de inestabilidad jurídica en la relación entre el fisco y el contribuyente, además de complicar los procedimientos administrativos y de control por parte de la administración tributaria [...].

Los cambios constantes a la legislación le restan certeza jurídica a los actos administrativos y generan oportunidades para cometer abusos, realizar actos discrecionales y prácticas de corrupción. Además de complicar el marco jurídico, la introducción de cambios frecuentes dificulta la aplicación de las leyes por parte de los contribuyentes, aumenta los costos de cumplimiento y vuelve más compleja la administración tributaria. (pp. 133, 149).

En segundo lugar, el desarrollo de los mercados financieros y de capitales ha conducido a consolidar un sistema hegemónico que se ha dado en denominar economía de mercado el cual tiene implicaciones de tipo fiscal, una de ellas caracterizada por desgravar las rentas movibles, aumentar gravámenes a las rentas menos movibles y fortalecer la tributación indirecta.

El sentido de esto, concordante con los postulados del Consenso de Washington, es fortalecer los impuestos al consumo que no afectan los beneficios empresariales y representan una mayor eficiencia en cuanto a su gestión, control y recaudo, materializando al mismo tiempo el principio de neutralidad. El costo de esta situación es la lesión sobre los impuestos progresivos con efectos redistribuidores puesto que también se pretende incentivar la atracción de capitales y localización de inversiones en las jurisdicciones de los Estados. De ahí que se desgrave el capital y se definan mecanismos tendientes a incrementar la tributación de las rentas con menor riesgo de "fuga" tales como las rentas de trabajo percibidas por las personas naturales.

Lo anterior ha sido llevado al plano legal y práctico durante los últimos treinta años mediante constantes reformas y ajustes fiscales en América Latina en general y en Colombia en particular, que ha permitido un 
incremento sostenido en los periodos recientes con una afectación generalizada en el recaudo durante la segunda mitad de la década pasada producto de la crisis financiera de Estados Unidos y algunos países emergentes (ver gráfico 2). De acuerdo con Naciones Unidas, CEPAL (2018)

en los países de América Latina se comenzaron a implementar ajustes fiscales más estrictos con el objetivo de alcanzar la estabilidad macroeconómica y la sustentabilidad fiscal en el menor tiempo posible. Por el lado de los ingresos, esto se hizo evidente a partir de varias reformas tributarias que consolidaron algunas tendencias ya iniciadas, como la ampliación gradual de la base imponible y el aumento de la alícuota general del impuesto al valor agregado (IVA). También debe mencionarse la supresión de una gran cantidad de tributos de escasa recaudación pero alto costo administrativo (simplificación) y la transformación de los impuestos específicos al consumo en equivalentes ad valorem (eficiencia). (p. 46).

\section{Gráfico 2}

Recaudación tributaria, América Latina y el Caribe y OCDE, 1990-2018

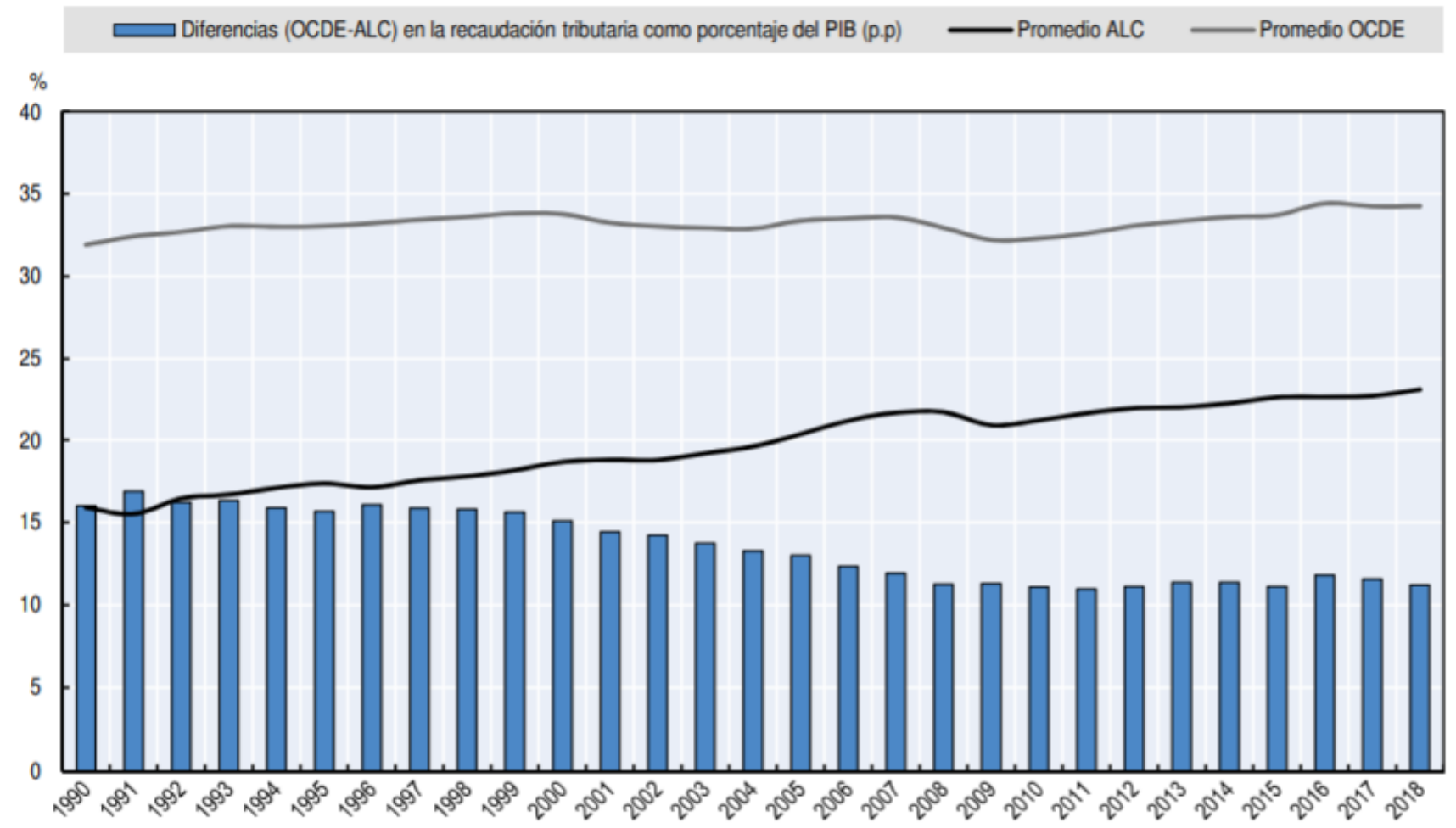

Fuente: OCDE et al (2020)

Desde estas perspectivas, se puede señalar una consolidación en América Latina de una tributación comprendida por diferentes tributos, pero basada fundamentalmente sobre los impuestos de renta y de IVA, tal y como se observar en el gráfico 3. 


\section{Gráfico 3}

Estructura tributaria promedio en América Latina y el Caribe, 1990 y 2018 . En \% del total de ingresos tributarios

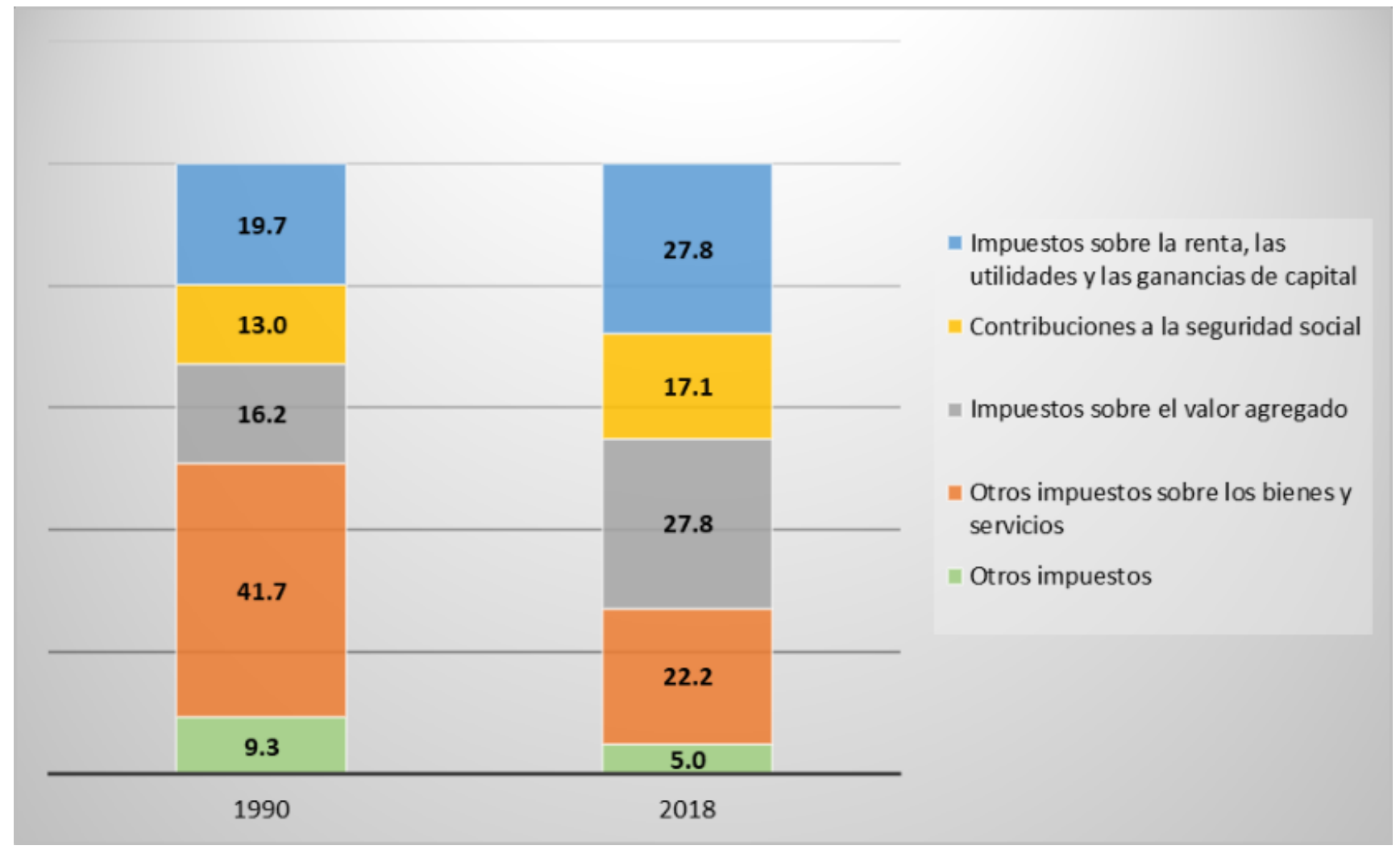

Fuente: Elaboración propia (2020) a partir de OCDE et al (2020)

De esta manera, se identifica una prevalencia de los impuestos que recaen sobre bienes y servicios, incluyendo el IVA que tiene un peso importante dentro de la estructura de recaudo de varios países latinoamericanos (ver gráfico 4). Esto da cuenta del "sesgo hacia la imposición indirecta, lo que tiene implicancias concretas en términos del impacto redistributivo de los sistemas tributarios de la región" (Naciones Unidas, CEPAL, 2018, p. 49) puesto que si bien desarrollan el criterio de eficiencia, lesionan el principio de equidad al no consultar la capacidad contributiva de las personas. 
Gráfico 4

Estructura tributaria en países de América Latina y el Caribe, 2018

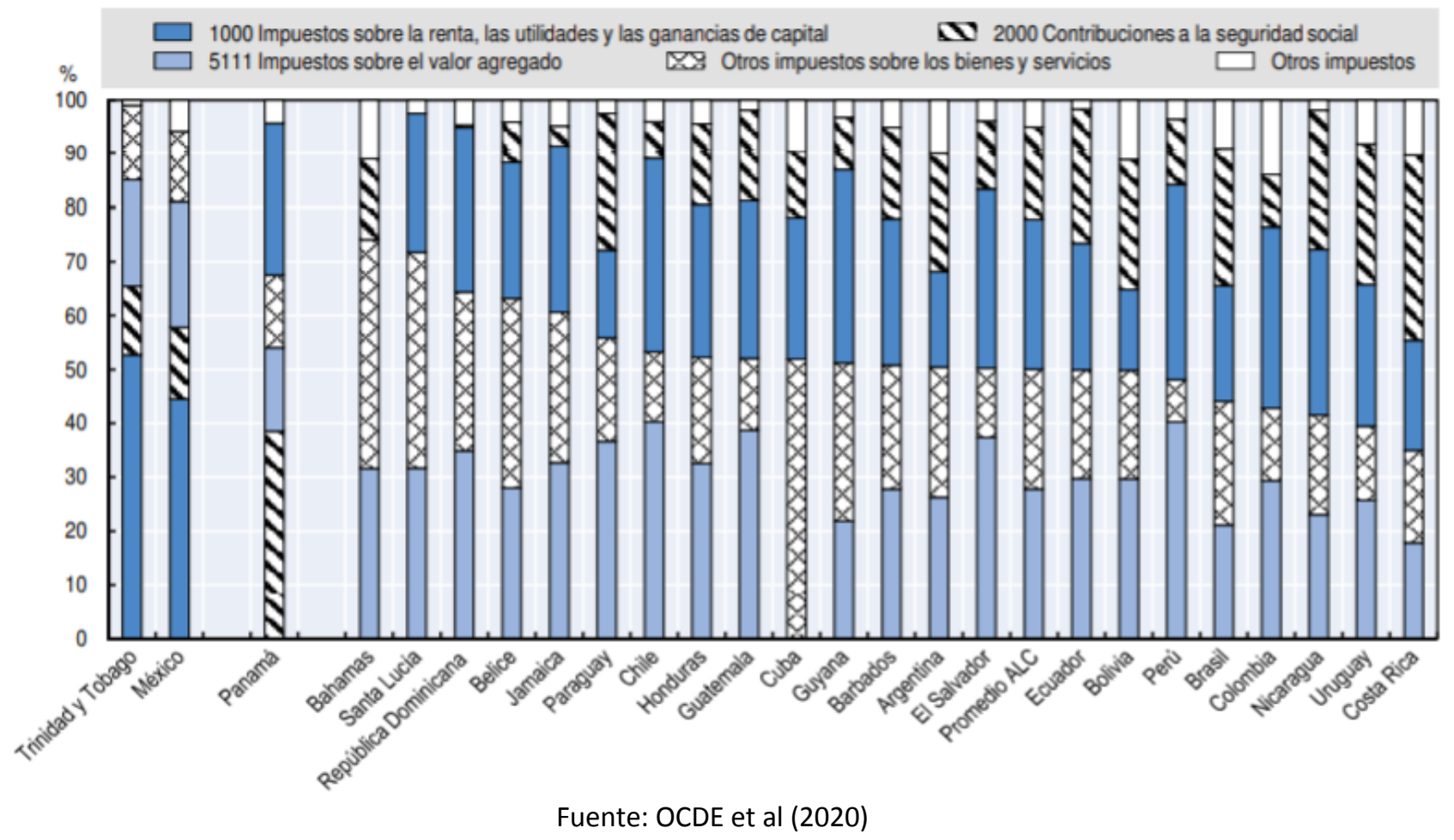

En el mismo sentido, Corbacho, Fretes y Lora (2012) advierten que "el sesgo latinoamericano hacia el IVA suele justificarse porque representa una opción más viable y sencilla de gestionar frente a las alternativas de imposición directa, especialmente sobre la renta personal" (p. 240). Así, con las continuas reformas se ha pretendido "ampliar la base de imposición del IVA ${ }^{3}$ en materia de bienes y servicios, al mismo tiempo que se considera que el énfasis debe ponerse en la tributación sobre el consumo [...] para no incidir adversamente en la formación de capital" (Gómez, 2006, p. 41). Existe de esta manera, un favorecimiento de la reproducción y concentración del capital a través de la política fiscal que limita la materialización de la justicia tributaria.

Una tercera tendencia de la tributación la constituye la competencia fiscal perniciosa entre países cuya finalidad es atraer capitales del exterior e incrementar la localización de inversiones en sus jurisdicciones. Para el efecto, se recurre al otorgamiento de incentivos fiscales y a disminuciones de los tipos impositivos lo cual implica costos y erosión de bases para los Estados que deben implementar estrategias conducentes a equilibrar el nivel de recaudo.

Frente a lo anterior, la Comisión Económica para América Latina y el Caribe (CEPAL)/Oxfam Internacional (2019) advierte que:

La región destaca por la generosidad de los beneficios ofrecidos a las empresas [...].

La reducción en las tasas del ISR de las empresas, la creación de nuevos incentivos a la inversión y el ofrecimiento de incentivos más generosos pone de manifiesto los problemas de la competencia fiscal internacional y el riesgo de una carrera a la baja en la tributación sobre la renta corporativa.

${ }^{3}$ Impuesto al valor agregado. 
Estas medidas erosionan las bases tributarias de los países y perjudican la movilización de recursos internos que son imprescindibles para financiar las políticas públicas necesarias para lograr los ODSs. (págs. 7-8)

Como consecuencia de lo anterior, los ajustes en los ordenamientos tributarios adelantados por la mayoría de los países y la liberalización de los mercados, han llevado a que las empresas multinacionales redefinan sus estructuras de planificación fiscal y sus decisiones de inversión a nivel mundial buscando jurisdicciones con tratamientos fiscales favorables para la localización de sus portafolios. Esto puede llevar a la erosión de las bases para determinados fiscos pero al mismo tiempo hacer más compleja su fiscalización por parte de las respectivas autoridades tributarias.

Por otra parte, la dinámica económica ha permitido el crecimiento y expansión de operaciones transfronterizas con lo cual se ha hecho necesario diseñar mecanismos tendientes a evitar la doble imposición entre Estados, lo cual constituye otra de las tendencias a señalar. Aunque en la mayoría de jurisdicciones se cuenta con instrumentos domésticos para el efecto (p.e. tax credit), los tratados internacionales para evitar la doble imposición se han ido configurando en el mecanismo expedito para lograr este cometido, pero también para facilitar la localización de inversiones y para la apertura de nuevos mercados. Así, Carbajo y otros (2017) plantean que

la red de CDI de los países de América Latina ha ido creciendo durante los últimos años, si bien aún se está muy lejos de la situación de los países desarrollados, existe un marcado avance respecto del estado de situación que podía observarse a principios de este siglo. (pág. 233).

No obstante, conviene reflexionar sobre el hecho de que

La celebración de tratados tributarios mediante los modelos más utilizados (ONU/OCDE) para resolver el «supuesto problema» de la doble imposición internacional conlleva un sacrificio fiscal para los países en desarrollo (PED), en general no compensado por las «supuestas mayores inversiones« con las que se intenta justificar la suscripción de los mismos. En cambio, a los países desarrollados (PD) les significa un indudable aumento de recaudación en relación con la situación ex ante, previa a la entrada en vigor de un tratado, que resulta de la aplicación plena de las legislaciones nacionales de los dos Estados involucrados. (Figueroa, 2012, pág. 130)

De esta manera, si bien los tratados internacionales para evitar la doble imposición contribuyen a la atracción de capitales extranjeros, podrían al mismo tiempo erosionar las bases recaudatorias, creando desventajas para los países receptores de inversión y limitando su crecimiento económico.

De otro lado, la expansión de los mercados también ha incrementado el fraude o abuso en materia tributaria a través de la aplicación indebida de los convenios para evitar la doble imposición -CDI-, la implementación de estructuras de planificación fiscal agresivas y hasta el ocultamiento de hechos generadores y realización de otras conductas evasivas o abusivas.

Como respuesta a lo anterior, los Estados vienen definiendo medidas antiabuso, generales y específicas, a nivel interno y en tratados internacionales que buscan sancionar tales conductas y determinar la sustancialidad económica y realidad de las operaciones, negocios y actos jurídicos. Derivado de lo anterior, la OCDE y el G20 lideran el proyecto BEPS compuesto por quince acciones (ver cuadro 1) que buscan evitar la erosión de bases y el traslado de beneficios las cuales se han ido incorporando paulatinamente en diversos ordenamientos 
tributarios en procura de la armonización y sincronización de medidas contra el fraude y abuso en materia tributaria.

Se resaltan los esfuerzos por asegurar la sujeción pasiva a gravámenes del comercio electrónico (economía digital); evitar el ocultamiento de información asociada a las estructuras de planificación fiscal internacional de carácter agresivo; limitar la erosión de las bases de recaudo y la utilización abusiva de convenios fiscales, entre otras.

Como complemento de lo anterior, se viene consolidando una tendencia marcada por la inclusión en los CDI de cláusulas sobre intercambio automático de información o la suscripción de tratados internacionales cuyo objeto específico es el intercambio automático de información tributaria-All- entre países. En ambos casos, el propósito es que las administraciones tributarias puedan aportar-recibir cooperación para la fiscalización de los contribuyentes y de sus respectivas operaciones a efectos de determinar la sustancialidad económica y realidad de las mismas, evitando erosiones sobre el recaudo y abusos en materia tributaria.

Ahora bien, la creciente preocupación por el deterioro del medio ambiente y el calentamiento global ha llevado a configurar una nueva tendencia a nivel tributario, consistente en la creación de impuestos ambientales, que aunque reciente, empieza a ofrecer ciertas ventajas como correctores de los impactos ecológicos causados por las actividades productivas y los hábitos de consumo. Así, impuestos al carbono, a la utilización de material plástico, las tasas de compensación, entre otros instrumentos, apuntan a estos fines. El gráfico 5 presenta los avances en esta materia en América Latina durante la última década.

\section{Cuadro 1}

Acciones del Proyecto OCDE/G20 sobre la Erosión

de la Base Imponible y el Traslado de Beneficios

\begin{tabular}{|c|c|c|c|c|}
\hline $\begin{array}{c}\text { Acción } 1 \\
\text { Abordar los retos de } \\
\text { la economía digital } \\
\text { para la imposición }\end{array}$ & $\begin{array}{c}\text { Acción } 2 \\
\text { Neutralizar los } \\
\text { efectos de los } \\
\text { mecanismos híbridos }\end{array}$ & $\begin{array}{c}\text { Acción } 3 \\
\text { Refuerzo de la } \\
\text { normativa sobre } \\
\text { transparencia fiscal } \\
\text { internacional (CFC por } \\
\text { sus siglas en inglés) }\end{array}$ & $\begin{array}{c}\text { Acción } 4 \\
\text { Limitar la erosión de la } \\
\text { base imponible por vía } \\
\text { de deducciones en el } \\
\text { interés y otros pagos } \\
\text { financieros }\end{array}$ & $\begin{array}{c}\text { Acción } \mathbf{5} \\
\text { Combatir las } \\
\text { prácticas fiscales } \\
\text { perniciosas, teniendo } \\
\text { en cuenta la } \\
\text { transparencia y la } \\
\text { sustancia }\end{array}$ \\
\hline \multirow[t]{2}{*}{$\begin{array}{c}\text { Acción } 6 \\
\text { Impedir la utilización } \\
\text { abusiva de } \\
\text { convenios fiscales }\end{array}$} & \multirow[t]{2}{*}{$\begin{array}{c}\text { Acción } 7 \\
\text { Impedir la elusión } \\
\text { artificiosa del } \\
\text { estatuto de } \\
\text { establecimiento } \\
\text { permanente (EP) }\end{array}$} & $\begin{array}{l}\text { Acciones } 8 \\
\text { Precios de } \\
\text { Transferencia: } \\
\text { Intangibles }\end{array}$ & $\begin{array}{c}\text { Acción } \mathbf{9} \\
\text { Precios de } \\
\text { Transferencia: Riesgos } \\
\text { y Capital }\end{array}$ & $\begin{array}{c}\text { Acción } 10 \\
\text { Precios de } \\
\text { Transferencia: Otras } \\
\text { transacciones de alto } \\
\text { riesgo }\end{array}$ \\
\hline & & \multicolumn{3}{|c|}{$\begin{array}{l}\text { Asegurar que los resultados de los precios de transferencia están en línea } \\
\text { con la creación de valor }\end{array}$} \\
\hline $\begin{array}{c}\text { Acción } 11 \\
\text { Evaluación y } \\
\text { seguimiento de BEPS }\end{array}$ & $\begin{array}{c}\text { Acción } 12 \\
\text { Exigir a los } \\
\text { contribuyentes que } \\
\text { revelen sus } \\
\text { mecanismos de } \\
\text { planificación fiscal } \\
\text { agresiva }\end{array}$ & $\begin{array}{c}\text { Acción } \mathbf{1 3} \\
\text { Reexaminar la } \\
\text { documentación sobre } \\
\text { precios de } \\
\text { transferencia }\end{array}$ & $\begin{array}{c}\text { Acción } 14 \\
\text { Hacer más efectivos } \\
\text { los mecanismos de } \\
\text { resolución de } \\
\text { controversias }\end{array}$ & $\begin{array}{c}\text { Acción } 15 \\
\text { Desarrollar un } \\
\text { instrumento } \\
\text { multilateral que } \\
\text { modifique los } \\
\text { convenios fiscales } \\
\text { bilaterales }\end{array}$ \\
\hline
\end{tabular}

Fuente: Elaboración propia (2018) a partir de OCDE (2015) 
Gráfico 5

Elementos ambientales en las Reformas Tributarias de la última década en América Latina

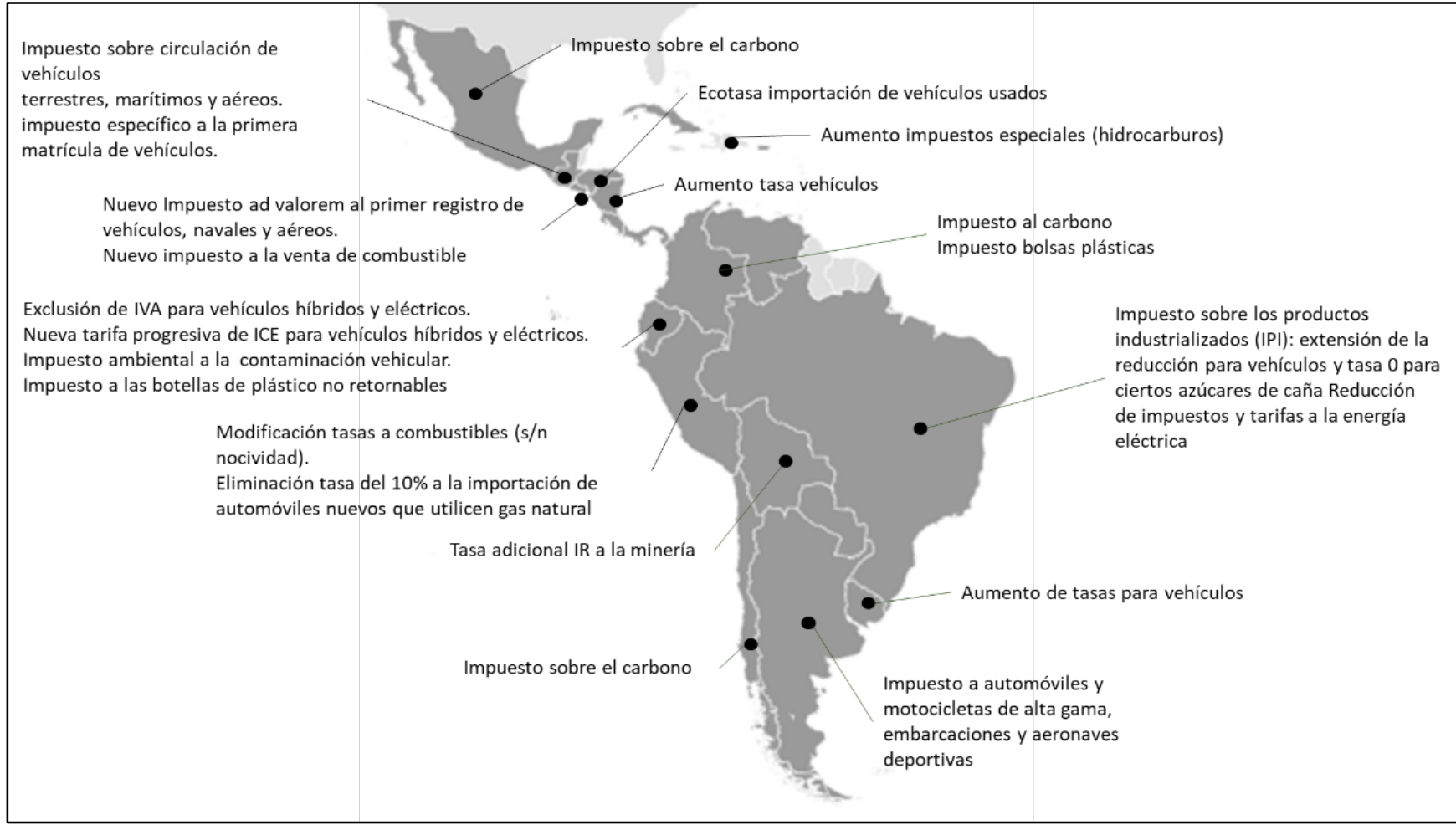

Fuente: Elaboración propia (2020) a partir de Fanelli, Jimenez y López (2015)

Por su parte, el gráfico 6 presenta la estructura de ingresos tributarios relacionados con el medio ambiente por base imponible principal en el año 2018, la cual permite inferir que el recaudo se concentra fundamentalmente en gravámenes sobre energía y transporte pero al mismo tiempo permite señalar que faltan mecanismos legales en los ordenamientos tributarios desde la perspectiva extrafiscal orientados a corregir el impacto o desincentivar actividades contaminantes o de explotación de recursos naturales y recursos no renovables.

El gráfico 7, presenta la estructura tributaria de los ingresos tributarios subnacionales en 2017. Existe una disparidad en la medida en que mientras algunos países tales como Guatemala, Perú, Uruguay, entre otros, enfatizan el recaudo en impuestos sobre la propiedad; otro grupo de Estados como Panamá, Brasil, Nicaragua, Argentina y Colombia lo hacen con impuestos que gravan la producción de bienes y prestación de servicios lo cual constituye uno de los elementos de regresividad de los sistemas impositivos en el nivel subnacional.

Con todo, se debe seguir fortaleciendo la autonomía de los gobiernos subnacionales y la descentralización fiscal, consolidando la generación de ingresos tributarios propios para no depender totalmente de las trasferencias de los gobiernos centrales. Al respecto, Romero y Gómez (2018) exponen algunas recomendaciones generales de la OCDE en materia de autonomía tributaria y tributos subnacionales destacando que en este nivel debe haber equilibrio entre los ingresos tributarios y las transferencias provenientes del nivel central tratando de inclinar la balanza hacia las rentas fiscales propias. Asimismo, debe existir variedad en la base imponible de los Gobiernos subnacionales. 
Gráfico 6

Ingresos tributarios relacionados con el medio

ambiente por base imponible principal, 2018

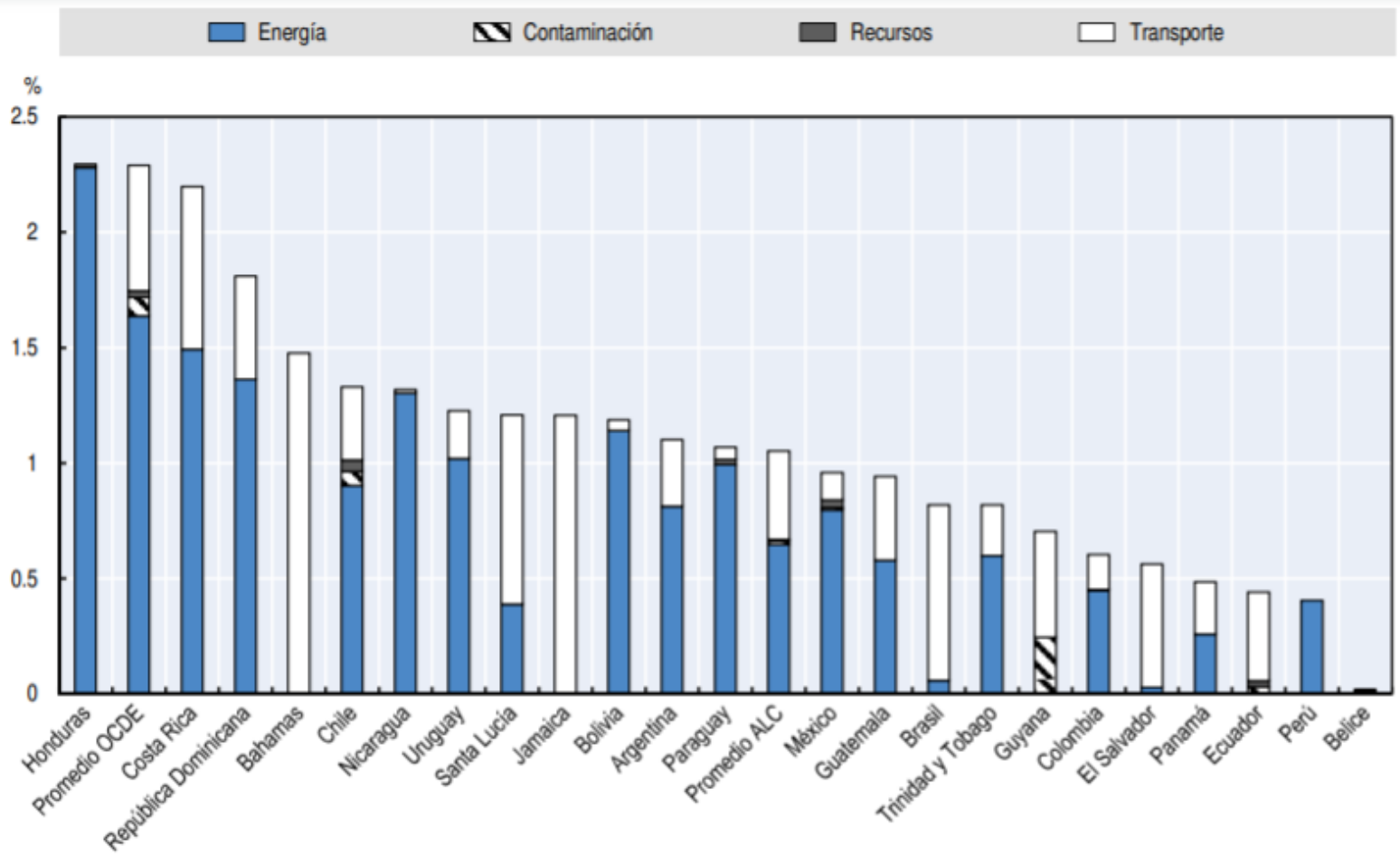

Fuente: OCDE et al (2020)

Gráfico 7

Estructura tributaria de los ingresos tributarios subnacionales, 2017

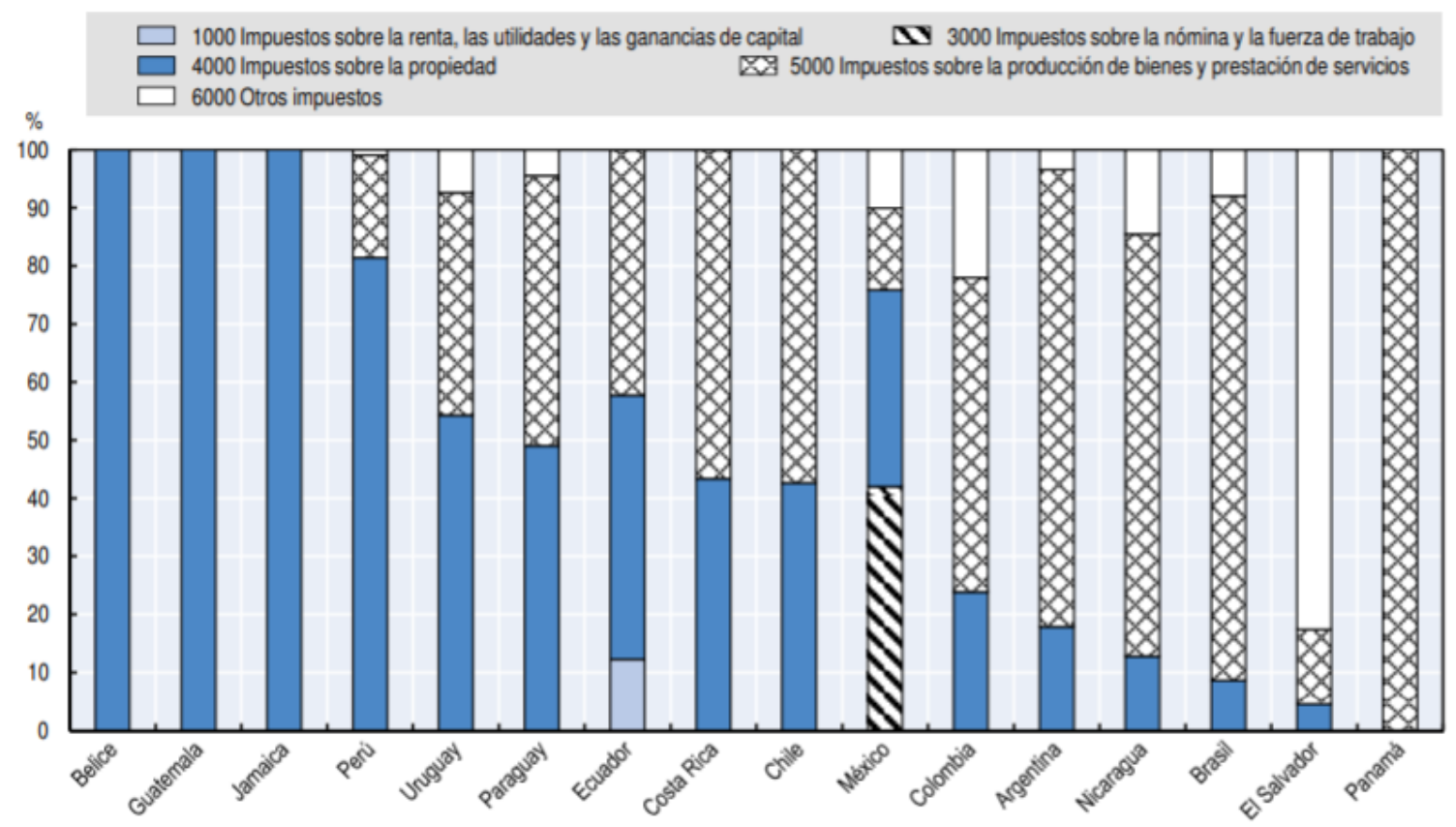

Fuente: OCDE et al (2020) 


\subsection{Desafíos de la tributación}

Algunos elementos considerados desafíos o tareas pendientes de la tributación en América Latina fueron anotados implícitamente en el aparte anterior. Se quiere en este punto señalar algunas cuestiones de manera precisa. Así, temas como la tributación ambiental resulta relevante en un mundo afectado por problemas que requieren acciones inmediatas. La tributación tendría un papel importante en este sentido en la medida en que podría incentivar ciertas actividades como procesos productivos sustentables, consumos ambientalmente responsables, entre otros; además de desincentivar otras actividades con impacto negativo sobre el medio ambiente.

Desde esta perspectiva y en el marco de la Agenda 2030 de Naciones Unidas para el desarrollo sostenible, Naciones Unidas, CEPAL (2018) propone una vinculación de los ODS con nuevas alternativas de tributación que fortalezcan los fiscos pero que además sirvan para atenuar los impactos ambientales (ver cuadro 2 ).

\section{Cuadro 2}

Alternativas innovadoras de política tributaria vinculadas con un conjunto de ODS seleccionados

\begin{tabular}{|l|l|}
\hline Objetivo del desarrollo sostenible & Reforma de política tributaria \\
\hline 6. Agua limpia y saneamiento & $\begin{array}{l}\text { Impuestos sobre la extracción de agua } \\
\text { Tarifas de saneamiento }\end{array}$ \\
\hline 7. Energía asequible y no contaminante & $\begin{array}{l}\text { Gravámenes energéticos } \\
\text { Incentivos para la utilización de energías renovables }\end{array}$ \\
\hline 8. Trabajo decente y crecimiento económico & $\begin{array}{l}\text { Incentivos tributarios para el consumo y la producción eficiente } \\
\text { Reducción de gravámenes distorsivos sobre el factor de trabajo }\end{array}$ \\
\hline 9. Industria, innovación e infraestructura & $\begin{array}{l}\text { Motivación de la inversión privada en investigación y desarrollo (+D) } \\
\text { de tecnologías verdes por medio de incentivos fiscales }\end{array}$ \\
\hline 10. Reducción de las desigualdades & Incremento de la progresividad de los sistemas tributarios \\
\hline 11. Ciudades y comunidades sostenibles & $\begin{array}{l}\text { Impuestos ambientales: contaminación sonora, del aire y del agua } \\
\text { Impuestos sobre la generación de residuos }\end{array}$ \\
\hline 12. Producción y consumo responsables & $\begin{array}{l}\text { Incentivos económicos para el uso eficiente de los recursos } \\
\text { naturales: gravámenes sobre la forestación, } \\
\text { Impuestos sobre la generación de basura } \\
\text { Impuestos sobre la utilización de bolsas plásticas }\end{array}$ \\
\hline
\end{tabular}

Fuente: Extractado de Naciones Unidas, CEPAL (2018)

Por otra parte, el crecimiento de operaciones con bases de moneda no homogénea tales como los criptoactivos o criptomonedas, también demanda acciones de las autoridades fiscales en cuanto a su fiscalización y sujeción pasiva a gravámenes. De facto, las transacciones con Bitcoin, una de las criptomonedas más reconocida, ha crecido exponencialmente en los últimos años (ver gráfico 8). 


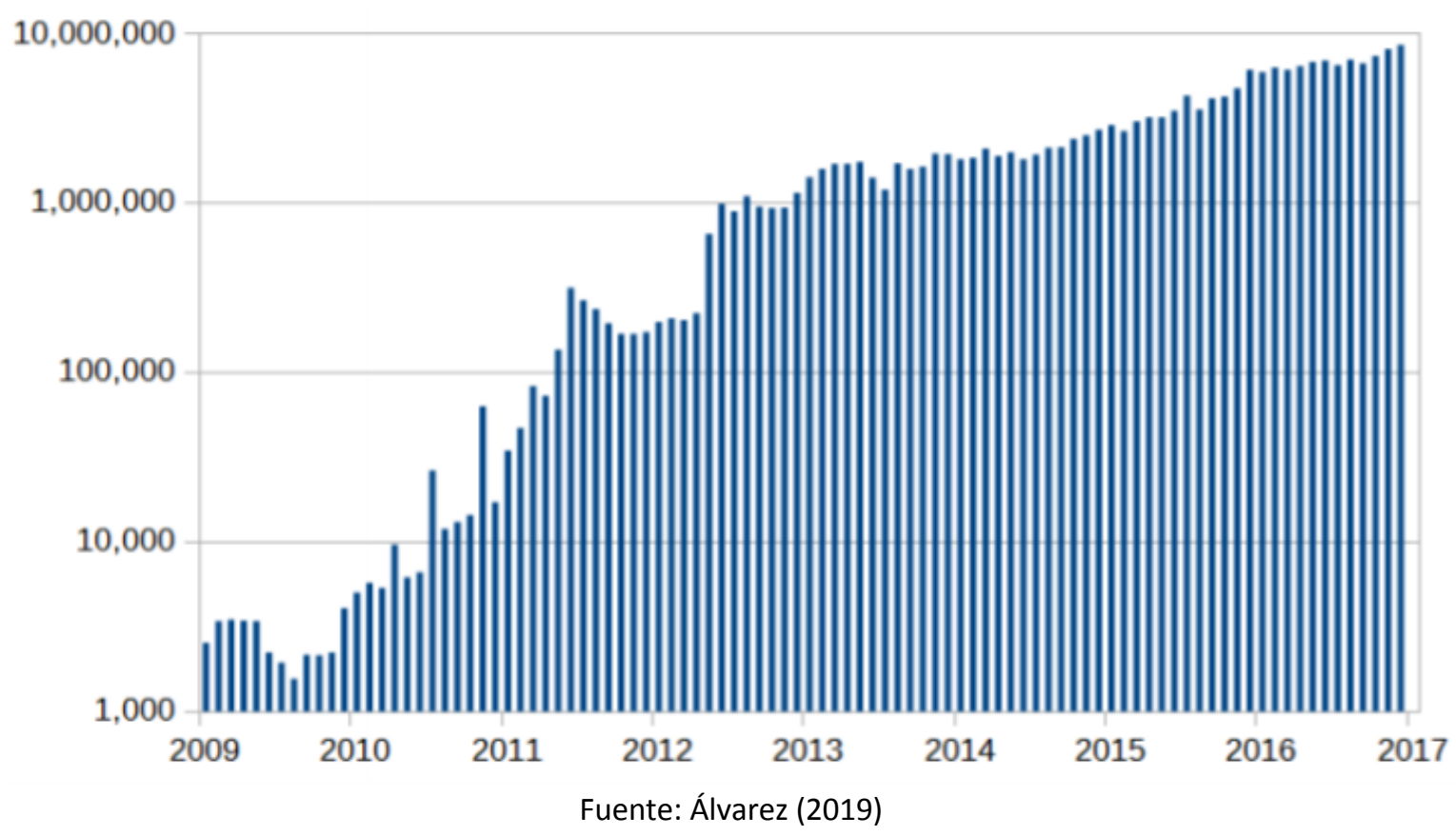

Un tercer desafío de la tributación refiere al fortalecimiento de los mecanismos legales y acciones administrativas para contrarrestar la evasión y elusión tributarias, tanto a nivel doméstico como a nivel internacional. En relación con esto, las operaciones y localización de inversiones en jurisdicciones no cooperantes conducen a un deterioro del sistema normal de producción y distribución de bienes y servicios pues suponen la pérdida de recursos para las economías reales e incrementa sus desigualdades.

Un cuarto punto que resulta relevante, es la creación o consolidación de cultura tributaria a través de la promoción de la transparencia y rendición de cuentas por parte de las autoridades fiscales con lo cual se ganaría en calidad del gasto público -especialmente el de inversión social, legitimidad y confianza por parte de los contribuyentes y población en general. Esto motivaría también el cumplimiento voluntario de los deberes formales y promueve la conciencia de la contribución al sostenimiento de los gastos del Estado dentro de los principios rectores de la tributación, desarrollando la solidaridad y subsidiariedad propias del modelo de Estado Social de Derecho.

Se trata de desarrollar adecuadamente el ciclo de la contribución en el que los ciudadanos contribuyen, el Estado administra eficientemente los ingresos tributarios mediante la planificación y asignación del gasto público en programas de educación, salud, vivienda, ambiente sano y suministro de bienes públicos, la ciudadanía se convierte en vigía de dicha administración y se asegura el bienestar social de la población bajo criterios de igualdad y equidad.

Ahora bien, para conseguir este cometido también se hace necesario concebir reformas fiscales estructurales, que den solución a los problemas de fondo en materia económica, social y ambiental, y que protejan a los sistemas impositivos de los constantes cambios en el marco de las máximas de certeza y legalidad. De ahí que Baer (2006) plantee como desafío de los países latinoamericanos la reducción de la "incertidumbre en cuanto a la estructura del sistema impositivo y tornarlo más estable y predecible" (p. 147) lo cual se podría lograr con sistemas simples, estables y transparentes.

Un desafío más de la tributación, quizás el más importante al considerársele englobante de los demás, concierne al hecho de potenciar los tributos para el goce de las libertades fundamentales y el desarrollo de los derechos humanos. Esta idea conduce a plantear que el tributo contiene en sí mismo un espíritu de justicia, en tanto su 
finalidad es resolver conflictos sociales. De ahí que la tributación deba orientarse a satisfacer los derechos de la población de manera progresiva; cerrar las brechas de inequidad y desigualdad socioeconómica; servir, conjuntamente con los subsidios, como instrumento de redistribución de la renta y la riqueza; incentivar o desincentivar, según el impacto sobre la sociedad, la economía y el medio ambiente, actividades, hábitos de consumo, procesos productivos y extractivos; y mejorar la progresividad del sistema tributario en su conjunto, ello es, no solo del impuesto sobre la renta que es por naturaleza progresivo, sino del sistema tributario de manera integral.

Se reconocen los esfuerzos de la mayoría de países de la región por avanzar en la redistribución de la renta y la riqueza a partir de los instrumentos de política fiscal (impuestos y transferencias) y disminución de los niveles de desigualdad, pero ello se ve limitado por el modelo de economía de mercado y los fundamentos que soportan los sistemas impositivos.

La situación en este aspecto es crucial toda vez que las tasas de pobreza y pobreza extrema en Latinoamérica presentan niveles considerablemente altos y mantienen resultados más o menos constantes desde el año 2008 (ver gráfico 9), lo que significa que las políticas públicas definidas hasta ahora no han logrado, en términos generales, resolver esta problemática.

Gráfico 9

América Latina (18 países): tasas de pobreza y pobreza extrema, y personas en situación de pobreza y pobreza extrema, 2002-2019 (en \%)

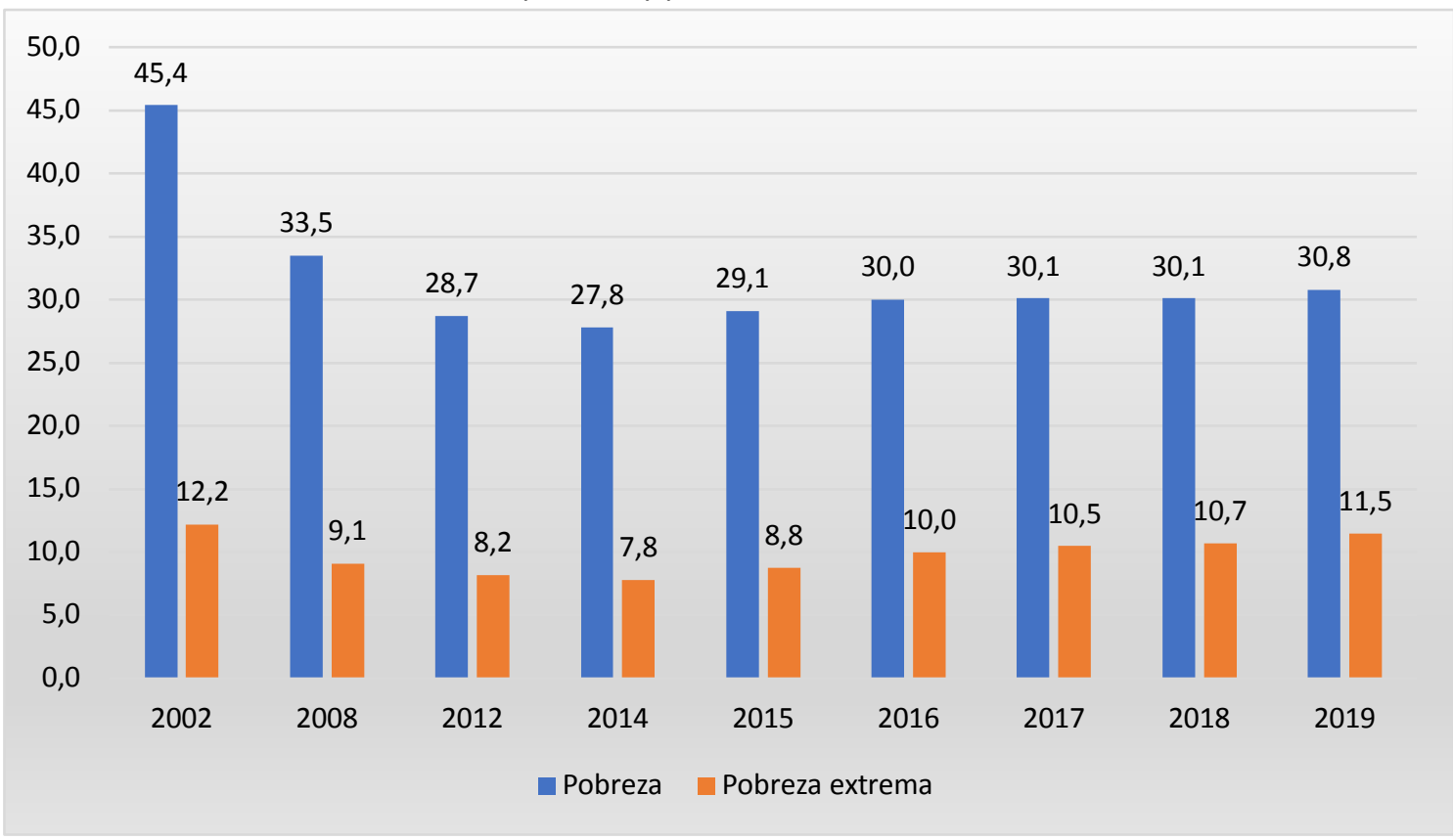

Fuente: Elaboración propia (2020) a partir de Comisión Económica para América Latina y el Caribe (CEPAL) (2019).

Por su parte, el gráfico 10 indica el reparto de la pobreza en América Latina para el año 2019, dejando en evidencia que los países que presentan niveles en este sentido por encima del $25 \%$ son: Honduras, Guatemala, Venezuela, México, Nicaragua, El Salvador y Colombia; y que los países con mejor desempeño en cuanto a este indicador son Uruguay, Chile, Argentina y Costa Rica. 


\section{Gráfico 10}

El reparto de la pobreza en América Latina. \% de la población que es pobre, muy pobre y extremadamente pobre

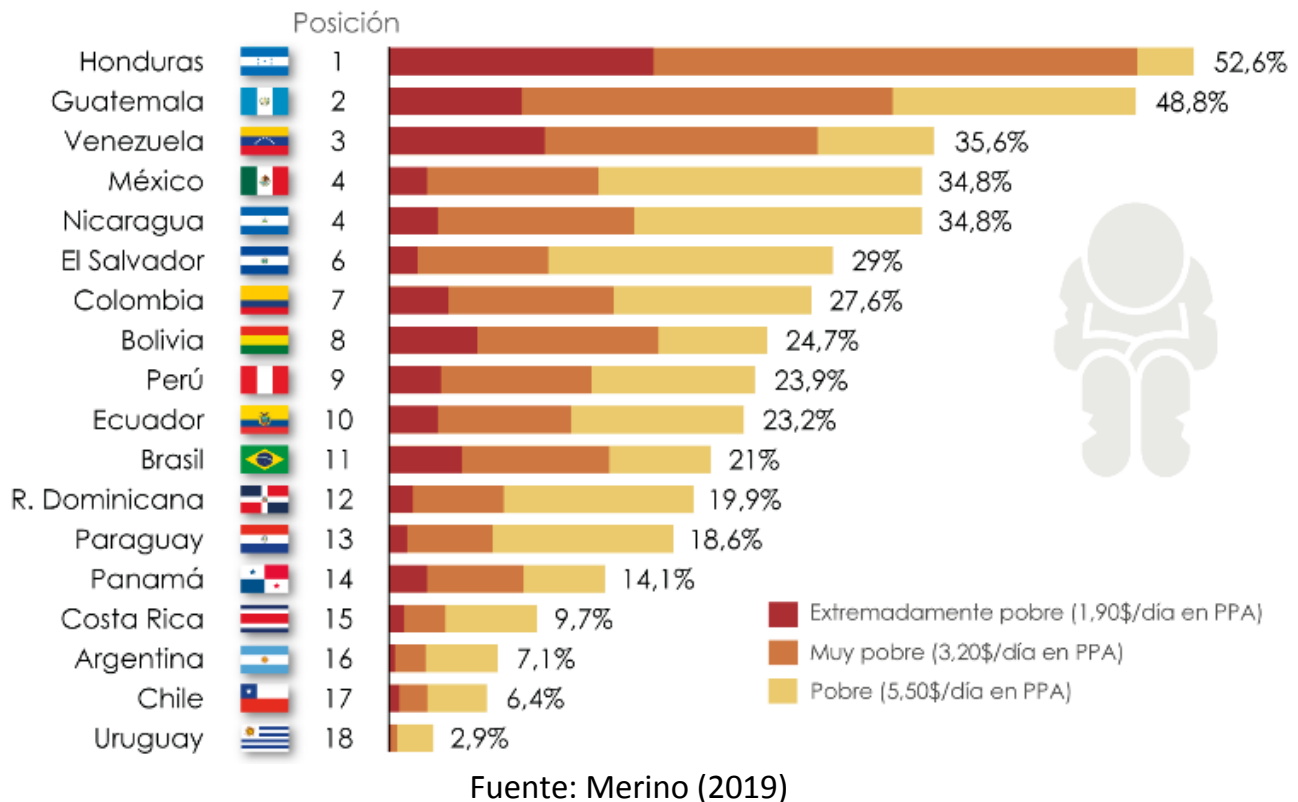

Otro indicador que denota la problemática analizada es la desigualdad. El gráfico 11 presenta el porcentaje de la renta que obtuvo el $20 \%$ más rico de la población en 2017 , en la que se observa en general, un alto nivel de concentración en la mayoría de países. En el caso de Ecuador, Chile, Panamá, México, Colombia y Brasil, el indicador presenta resultados superiores al $50 \%$, es decir, el $20 \%$ más rico de la población concentra más del 50\% de los ingresos generados.

\section{Gráfico 11}

La desigualdad en América Latina. Porcentaje de los ingresos totales que obtiene el 20\% más rico de la población. Datos de 2017

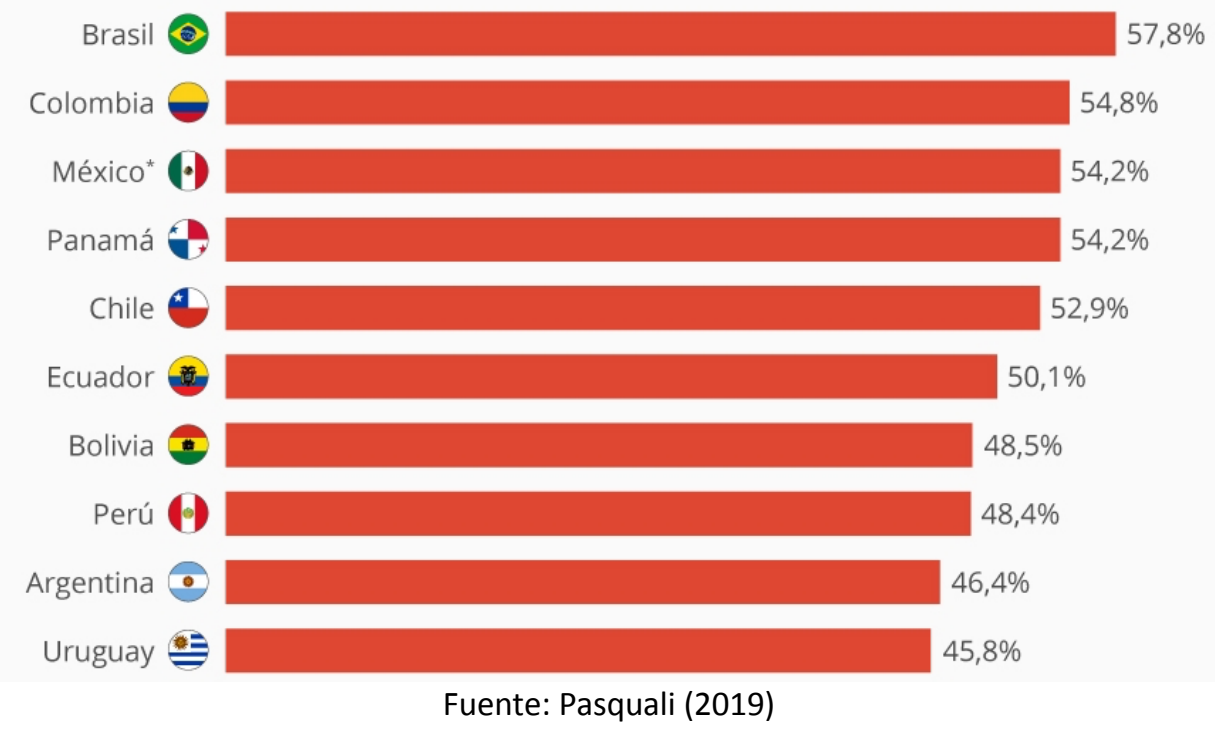

En la misma línea, el indicador que suele utilizarse para la medición de la desigualdad es el Gini, el cual si bien mejora desde 2002 en todos los países, para 2018 todavía se mantiene cercano a 0,5 con excepción de Argentina y Uruguay (ver gráfico 12). Lo anterior coloca a la región como una de las más desiguales del planeta. Esta situación se agrava por el hecho de que los instrumentos de política fiscal, impuestos y transferencias, no 
mejoran sustancialmente el indicador de desigualdad. Así, mientras en países desarrollados se percibe el efecto corrector y redistribuidor de los impuestos y transferencias, en Latinoamérica es poco notorio dicho efecto (ver gráfico 13). Los países con mejor desempeño en el proceso corrector y redistribuidor son Uruguay, Argentina y Brasil, pero aun así siguen alejados de los indicadores de países desarrollados y países OCDE.

\section{Gráfico 12}

América Latina (15 países): índice de desigualdad de Gini, 2002-2018.

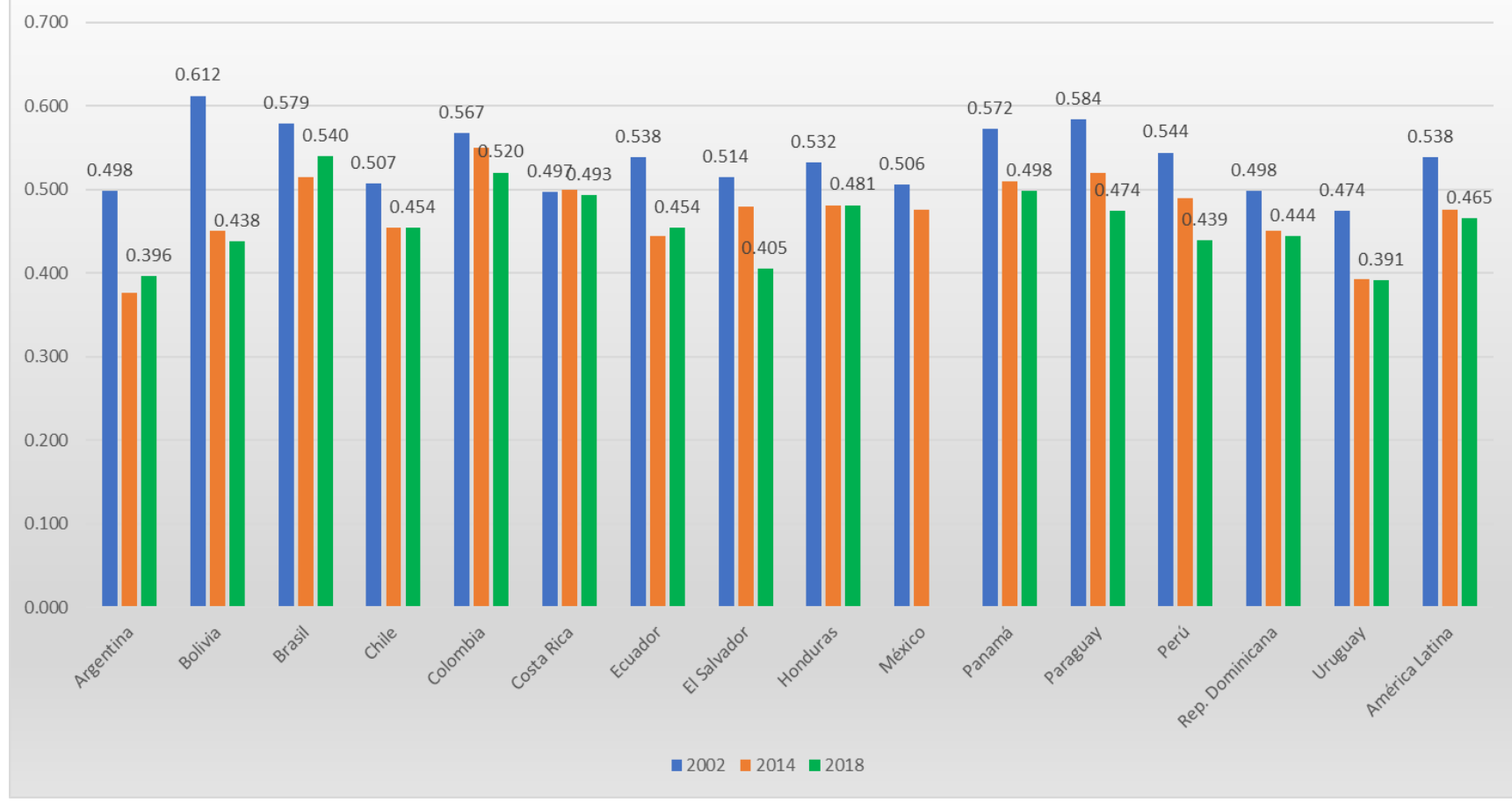

Fuente: Comisión Económica para América Latina y el Caribe (CEPAL) (2019)

\section{Gráfico 13}

Diferencias en la desigualdad de ingresos antes y después de ingresos y transferencias gubernamentales

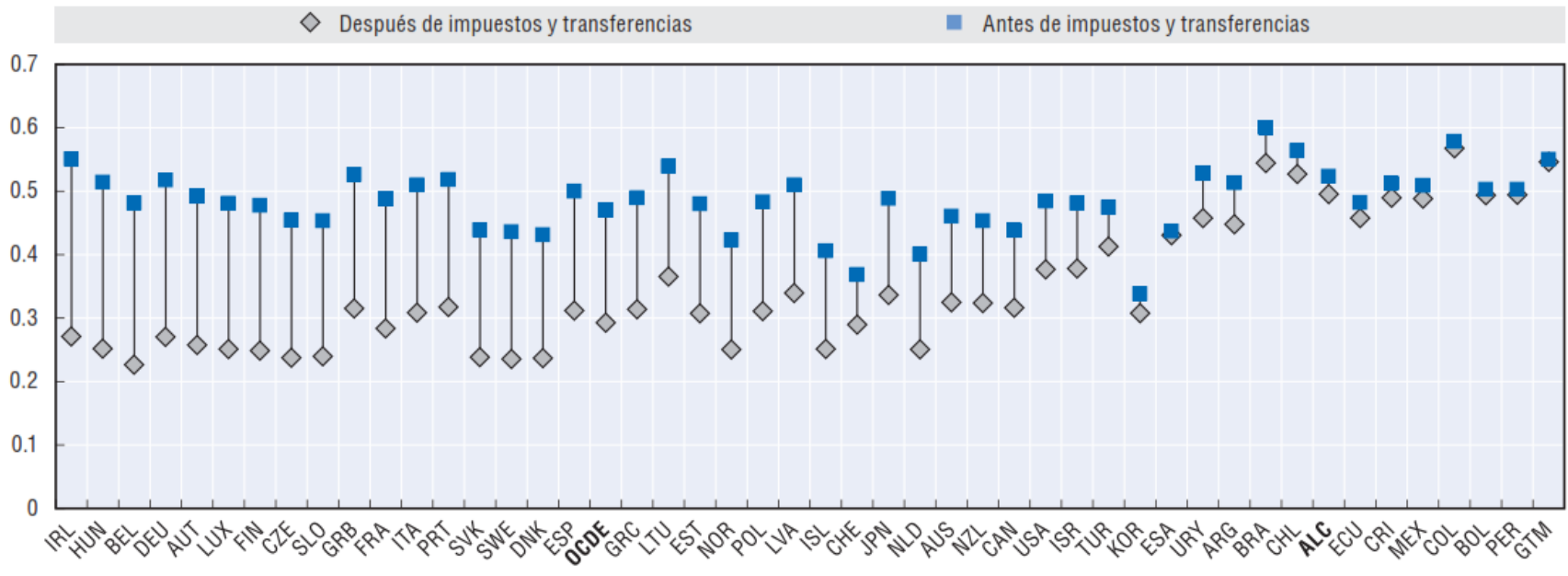

Fuente: OCDE (2016)

Pasando a otro desafío, se deben definir medidas que fortalezcan la capacidad fiscal de los Estados lo cual supone revisar y ajustar privilegios y beneficios tributarios; modernizar las administraciones tributarias en orden a 
simplificar, reducir costos de cumplimiento, mejorar la gestión y la cooperación administrativa; fortalecer las acciones de formalización y legalización de actividades económicas; y evitar las amnistías; entre otros. Vale la pena proponer el debate frente a algunas de estas medidas dada su relevancia. Así, la creación de exenciones y beneficios tributarios reducen la recaudación, implican un costo financiero para el Estado (gasto tributario) y producen ineficiencia en el sistema impositivo. Algunas de estas exenciones no se orientan hacia el propósito esencial de las mismas, el cual es el de favorecer a la población vulnerable y promover e impulsar algunas actividades económicas rezagadas, sino que tienen más bien el propósito de favorecer intereses particulares en tanto "tienden a beneficiar a los segmentos de población más ricos frente a los más pobres" (Centro de Desarrollo de la Organización para la Cooperación y el Desarrollo Económico, 2007, p. 50), es decir, se favorecen las rentas de capital. Países como Argentina, Chile, Colombia, Ecuador, El Salvador, Honduras, Guatemala, Nicaragua, Perú, México y Brasil, entre otros, han establecido exenciones tributarias, por ejemplo, para los sectores hotelero y agropecuario; de las cuales se han beneficiado más los ricos que los pobres y han elevado el gasto tributario derivado de las mismas en estos países. También ha sido común en varios de estos países la autorización a deducir de la base gravable del impuesto sobre la renta un porcentaje de la adquisición de activos fijos lo cual se traduce en "un beneficio que está altamente concentrado en la población de altos ingresos, por lo que tiene un impacto negativo en la distribución del ingreso" (Agostini y Jorratt, 2013, p. 60).

En el Cuadro 3 se presenta el número de exenciones tributarias a la inversión por país, estableciéndose que la mayor parte de beneficios son sectoriales dentro de los cuales se incentiva tales inversiones.

Frente al tema de las exenciones, Barajas (2011) plantea de una parte que los fines de éstas son: "atraer la inversión extranjera directa o incentivar algún sector de la economía que por algún motivo se vea vulnerado o esté rezagado frente a otros, o incluso estimular la producción de excedentes exportables" (p. 239). Por otra parte, señala este mismo autor que con las exenciones "se propicia una particular forma de inequidad al otorgar exenciones tributarias a un pequeño grupo de privilegiados que tienen suficientes recursos para pagar sus obligaciones tributarias correspondientes por ley" (Barajas, 2011, p. 239). Lo anterior implica que la existencia de exenciones favorece la concentración y reproducción del capital. Peor aún resulta el hecho de que el costo de los beneficios fiscales concedidos a los grandes capitales (gasto tributario), representado básicamente en disminuciones en la recaudación, debe ser cubierto a través de los impuestos al consumo e imponiendo más gravámenes a las rentas de trabajo como se indicó anteriormente.

Por último, se hace mención de las amnistías concedidas por algunas haciendas públicas (Bolivia, Argentina y Colombia) que si bien tienen como propósito mejorar los niveles de recaudación, no generan confianza en los respectivos sistemas tributarios por parte de los sujetos pasivos, o por lo menos, de aquellos que cumplen oportunamente con sus deberes formales en materia fiscal. Lo anterior, obedece a que dichas amnistías han consistido en condonar deudas tributarias por concepto de impuestos, sanciones e intereses, respecto de aquellos contribuyentes que han incumplido con obligaciones y deberes formales.

Las amnistías por consiguiente, constituyen un instrumento fiscal que propende la eficiencia en la recaudación y la recuperación de la cartera, pero que afectan el cumplimiento tributario y, peor aún, lesionan la equidad e igualdad del sistema; principios sobre los que se edifica la justicia. Lo sucedido en España con la expedición del Real Decreto Ley 12 de 2012 que introduce la figura de la amnistía frente a algunas omisiones e incumplimientos tributarios constituye un ejemplo de ello, como comenta Sánchez (2013). Para este autor, la amnistía tributaria es una medida extrafiscal que "mira más al importe económico que supone dicha recaudación que a la vigencia de los principios de tributación" (Sánchez, 2013, p. 116). De otra parte señala el mismo autor. 
Cuadro 3

Número de incentivo a la inversión por país y objetivo

\begin{tabular}{lllll}
\hline & \multicolumn{4}{l}{ Tipo de incentivo a la inversión } \\
\cline { 2 - 5 } País & General & Localización & Sectorial & Total \\
\hline Argentina & 4 & 6 & 29 & 39 \\
Chile & 10 & 7 & 2 & 19 \\
Colombia & 4 & & 12 & 16 \\
Ecuador & 15 & & 16 & 31 \\
El Salvador & 2 & & 8 & 10 \\
Guatemala & 1 & & 5 & 6 \\
Honduras & 1 & 4 & 27 & 32 \\
Nicaragua & & 1 & 66 & 67 \\
Perú & 2 & 6 & 8 & 16 \\
República Dominicana & & 7 & 94 & 101 \\
Total & $\mathbf{3 9}$ & $\mathbf{3 1}$ & $\mathbf{2 6 7}$ & $\mathbf{3 3 7}$ \\
\hline
\end{tabular}

Fuente: Agostini y Jorratt (2013)

[E]n la amnistía fiscal existe el peligro de que suponga premiar la ilicitud y desincentive el cumplimiento legal y puntual [...].

En definitiva, resulta una regulación que trata de manera singularizada y beneficiosa a los sujetos incumplidores de sus obligaciones tributarias. Se evidencia una desigualdad de trato justificada formalmente por la posibilidad de condonar deudas. Ahora bien, dicha justificación formal creemos que no es suficiente para evitar la discriminación que origina, y que lesiona el principio de igualdad constitucionalizado en el art 31.1 de la CE. En tal sentido trata de manera diversa, y de forma más favorable, a los sujetos incumplidores de las normas tributarias y eventual infractores de las mismas." (Sánchez, 2013, p. 116).

Desde esta perspectiva, las haciendas públicas deben asumir el desafío de "dar una señal clara de que los impuestos no se van a recaudar por vía de amnistías o condonaciones" (Baer, 2006, p. 151).

\section{Conclusiones}

La globalización económica, la desregulación y liberalización de los mercados han tenido incidencia sobre la modelación de los sistemas impositivos en los últimos cuarenta años, pasando de privilegiar la tributación directa ventajosa en cuanto a sus efectos progresivos y redistribuidores, a una tributación indirecta a la que se le acusa de ser regresiva pero que al mismo tiempo desarrolla a cabalidad los principios de eficiencia, neutralidad y no afectación del capital.

Sin embargo, este modelo económico y fiscal ha profundizado las problemáticas sociales y ambientales en América Latina relacionadas con la pobreza, concentración de la riqueza, altos niveles de desigualdad, población en situación de vulnerabilidad y con necesidades básicas insatisfechas; altos niveles de contaminación y destrucción de servicios ecosistémicos, entre otros.

En primer lugar, surge la pregunta en torno al papel de la tributación en la resolución de estos conflictos sociales y ambientales. La respuesta a esta pregunta problematizadora pasa en primer lugar, por comprender la dinámica de la tributación en los últimos años, lo que permitió identificar las principales tendencias que han caracterizado la modelación de los sistemas impositivos de la región, dentro de las que se cuentan las constantes reformas fiscalistas y coyunturales; el fundamento de las reformas en los desgravámenes al capital que al mismo tiempo ha provocado una competencia fiscal perniciosa, el incremento de los impuestos a las rentas de trabajo y el fortalecimiento de los impuestos al consumo; la ampliación de la red de tratados tributarios internacionales para evitar la doble imposición o para el intercambio de información tributaria; la creación de exacciones correctoras 
de externalidades negativas sobre el medio ambiente y el fortalecimiento de los impuestos subnacionales; entre otros.

En segundo lugar, se plantean algunos de los desafíos que debería atender la tributación en el futuro cercano en orden a mejorar el bienestar social de la población, cerrar las brechas de desigualdad y resolver los conflictos sociales y ambientales señalados. Desde esta perspectiva, cobra relevancia el fortalecimiento de la tributación ambiental (impuestos e incentivos fiscales verdes); la sujeción pasiva de ciertas operaciones o actividades que hoy son opacas para las autoridades fiscales tales como la economía digital, las operaciones en criptomonedas y las actividades informales; el fortalecimiento de la capacidad fiscal de las autoridades fiscales, de la cultura tributaria y del efecto corrector-redistribuidor de los impuestos.

Conviene en este punto precisar que además del fin recaudatorio que en general pretende el Estado con los impuestos, algunos de estos también pueden tener otro sentido, el de ser correctores de externalidades negativas y fallos del mercado con lo cual se devela no solo el carácter fiscal sino también extra fiscal que tienen los impuestos.

Desde esta perspectiva, se hace necesario ajustar la política tributaria en orden a mitigar las disparidades regionales, combatir la desigualdad y la pobreza, y promover un desarrollo socioeconómico sustentable, justo y equitativo a partir de garantizar un esquema de libertades y derechos fundamentales en igualdad de condiciones, sin privilegios injustificados. Adicional a esto, se debe concebir el establecimiento de diferencias, con criterios de equidad y progresividad, atendiendo contingencias biológicas, naturales, culturales, sociales y económicas, tanto en la creación de exacciones como en la asignación del gasto público.

\section{Referencias bibliográficas}

Agostini, C. y Jorratt, M. (2013). Política tributaria para mejorar la inversión y el crecimiento en América Latina. Santiago de Chile: Naciones Unidas.

Álvarez, L. J. (2019). Criptomonedas: Evolución, crecimiento y perspectivas del Bitcoin. Población y Desarrollo, 25(49), 130-142.

Baer, K. (2006). La administración tributaria en América Latina: algunas tendencias y desafíos. En Centrángolo, O. y Gómez, J.C. (Eds.). Tributación en América Latina. En busca de una nueva agenda de reformas (39130). Santiago de Chile: Comisión Económica para América Latina y el Caribe.

Barajas, R.C. (2011). Beneficios tributarios y su relación con el déficit fiscal en Colombia, durante el período comprendido entre los años 2005 y 2010. Revista de investigaciones UNAD Bogotá - Colombia, 02, 237263.

Carbajo, D., Díaz, F., Jiménez, J. P., Ramos, V. M., Pérez, P., Podestá, A., . . Zambrano, R. (2017). Los sistemas tributarios en América Latina. Madrid: Agencia Española de Cooperación Internacional para el Desarrollo e Instituto de Estudios Fiscales.

Comisión Económica para América Latina y el Caribe (CEPAL). (2019). Panorama Social de América Latina, 2019. Santiago: Comisión Económica para América Latina y el Caribe (CEPAL).

Comisión Económica para América Latina y el Caribe (CEPAL)/Oxfam Internacional. (2019). Los incentivos fiscales a las empresas en América Latina y el Caribe. Santiago: Comisión Económica para América Latina y el Caribe (CEPAL). Obtenido de https://oxfamilibrary.openrepository.com/bitstream/handle/10546/620921/rr-tax-incentives-businesseslatin-america-caribbean-090919-summ-es.pdf 
Corbacho, A., Fretes, V. y Lora, E. (2012). Recaudar no basta. Los impuestos como instrumento de desarrollo. Washington: Banco Interamericano de Desarrollo.

Fanelli, J. M., Jiménez, J. P., \& López, I. (2015). La reforma fiscal ambiental en América Latina. Santiago: Comisión Económica para América Latina y el Caribe (CEPAL).

Figueroa, A. H. (2012). ¿Tratados tributarios para evitar la doble imposición internacional o para transferir recursos de países en desarrollo a países desarrollados? Voces en el Fénix (14), 128-138.

Gómez, J.C. (2006). Evolución y situación tributaria actual en América Latina: una serie de temas para la discusión. En Centrángolo, O. y Gómez, J.C. (Eds.). Tributación en América Latina. En busca de una nueva agenda de reformas (39-130). Santiago de Chile: Comisión Económica para América Latina y el Caribe.

Merino, Á. (7 de agosto de 2019). La pobreza en América Latina. Obtenido de https://elordenmundial.com/mapas/pobreza-en-america-latina

Naciones Unidas. (2015). Transformar nuestro mundo: la Agenda 2030 para el Desarrollo Sostenible. Obtenido de: https://unctad.org/meetings/es/SessionalDocuments/ares70d1_es.pdf.

OCDE et al. (2020). Estadísticas tributarias en América Latina y el Caribe 2020, OECD Publishing. París: OCDE. Obtenido de https://doi.org/10.1787/68739b9b-en-es.

OCDE. (2016). Panorama de las Administraciones Públicas: América Latina y el Caribe 2017. París: Éditions OCDE. Obtenido de http://dx.doi.org/9789264266391-es

OCDE. (2019). Estadísticas tributarias. Obtenido de https://www.oecd.org/tax/tax-policy/brochure-estadisticastributarias-en-america-latina-y-el-caribe-2019.pdf

Organización para la Cooperación y el Desarrollo Económico -OCDE-. (2015). Proyecto OCDE/G20 sobre la Erosión de la Base Imponible y el Traslado de Beneficios. Informes finales 2015. Resúmenes. Paris: Organización para la Cooperación y el Desarrollo Económico -OCDE-.

Pasquali, M. (28 de noviembre de 2019). Las sociedades más desiguales de América Latina. Obtenido de https://es.statista.com/grafico/20133/la-concentracion-de-la-riqueza-en-latinoamerica/

Restrepo, J.C. (2005). Hacienda Pública. (7ạ Ed). Bogotá: Universidad Externado de Colombia.

Romero, C. A., \& Gómez, L. A. (2018). Recomendaciones de la OCDE sobre tributación en los gobiernos subcentrales: una aproximación al caso colombiano. Revista Instituto Colombiano de Derecho Tributario (78), 353-389.

Sánchez, M.A. (2013). Medidas tributarias anticrisis de España. Análisis específico de la amnistía fiscal. Revista de Derecho, 26(1), 95-117.

Stiglitz, J. (1986). La economía del sector público. Barcelona: Antoni Bosch, editor, S.A.

Esta obra está bajo una Licencia Creative Commons Attribución-NoCommercial 4.0 International

(c) BY-NC 